\title{
Prediction of elastic settlement of rectangular piled raft foundation
}

\author{
Jagat Jyoti Mandal ${ }^{\text {i) }}$ and Tapabrata Roy ii)
}

\begin{abstract}
i) Professor, Department of Civil Engineering, National Institute of Technical Teachers' Training \& Research, Kolkata, India. ii) Assistant Professor, Department of Civil Engineering, Camellia Institute of Technology, West Bengal University of Technology, Kolkata, India.
\end{abstract}

\begin{abstract}
A FE - BE coupling technique is used in the present study for prediction of elastic settlement of rectangular piled raft foundations. The raft is idealised as a thick plate freely resting on soil medium, which is idealised as a semi-infinite, isotropic and homogeneous elastic half -space. The plate and the half- space are two separate models in unilateral and frictional contact at the interface. Pile is idealised as a spring of equivalent stiffness, obtained from simplified approach based on elastic theory assuming it to be a shaft in the half-space. Boundary element method is employed to determine the soil stiffness matrix by inverting the soil flexibility matrix, using Mindlin's solution for a point load in half-space as a fundamental solution. Finite element method is employed to determine the raft stiffness matrix based on Mindlin's plate bending theory, which allows transverse shear deformation. Transformation of the boundary element matrices are carried out to make it compatible for coupling with plate stiffness matrix obtained from finite element method. Combined stiffness matrix of the soil-pile-raft system is obtained by summing up the stiffness of the soil-raft system and the stiffness contribution of the piles at selected locations. A computer programme is developed, based on the procedure describe above, in which discretisation is automatic and requires very nominal data input. Effect of pile parameter on settlement of a piled raft system subjected to uniformly distributed load is studied for different number and configuration of piles to demonstrate the efficacy of piled raft system in reducing settlement.
\end{abstract}

Keywords: Raft foundation, Piled raft foundation, Elastic half-space, Boundary element method, Finite element method, Coupling, Elastic settlement

\section{INTRODUCTION}

In designing piles as foundation support for structures, it is a common trend to include a pile cap for joining of the pile heads. The pile cap is designed for structural capacity only. But the pile cap has additional influence on the foundation system besides joining of pile heads and simple load transferring. The roll of the pile cap becomes significant if the cap is in direct contact with the foundation soil. A Piled Raft foundation acts as a composite construction consisting of three load bearing elements: piles, raft and subsoil. According to its stiffness, the raft distributes the total load of structures as contact pressure and over the piles in the ground. The piled raft concept needs evaluation of a number of factors in order to come up with analysis or design models that simulate the actual site conditions. The use of piled raft concept has lead to reduction of total as well as differential settlements. In many cases using raft foundation only induces excessive settlements which are not acceptable due to serviceability requirements. Placing of piles in systematic manner under the raft reduces such settlements to acceptable values. In addition to settlements, the bearing capacity of the whole system of foundation also improves. The conventional design methods used for pile groups lead to a higher number of piles under the raft. With the concept of piled raft, this number can be reduced. It is seen that piled rafts to be economical solution in foundation design for soil condition where such design is applicable.

\section{MATHEMATICAL FORMULATION}

The half-space response is based on the solution given by (Mindlin 1936) for a point load in half space, which allows taking into account the effect of embedment of the plate. The plate and the half-space are two separate models in unilateral and frictionless contact at the interface. Plate-half-space interface is discretised into two dimensional isoparametric quadrilateral quadratic elements and the plate is discretised into eight nodded isoparametric plate bending finite elements based on Mindlin's plate bending theory, which allows for transverse shear deformation. The stiffness matrix obtained from the boundary element method (by inverting the flexibility matrix) is coupled with the plate stiffness matrix 
obtained from the finite element method after transformation to get the stiffness matrix of the platehalf-space system [Mandal and Ghosh (1999)]. Pile is idealised as a spring of equivalent stiffness [Fig. 1(a) and (b)].
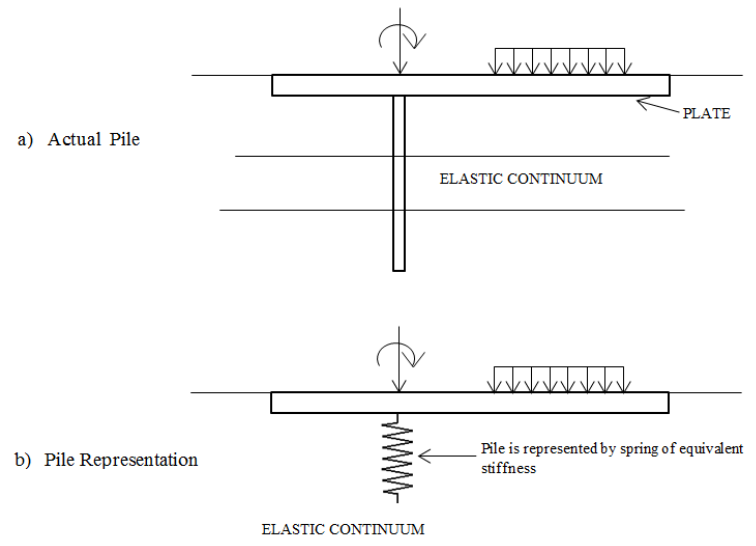

Fig. 1(a) \& (b) - Raft as plate on elastic continuum \& Pile represented by spring of equivalent stiffness.

The stiffness of the pile is obtained from simplified approach based on elastic theory [Poulos and Davis (1980)]. The pile is considered to be a shaft in the halfspace subjected to axial load of $\mathrm{P}$ at the ground surface (Fig. 2). The sides of the pile are assumed to be rough. The soil is considered to be an ideal homogeneous isotropic elastic half-space, having elastic parameters Es and $v_{\mathrm{s}}$.

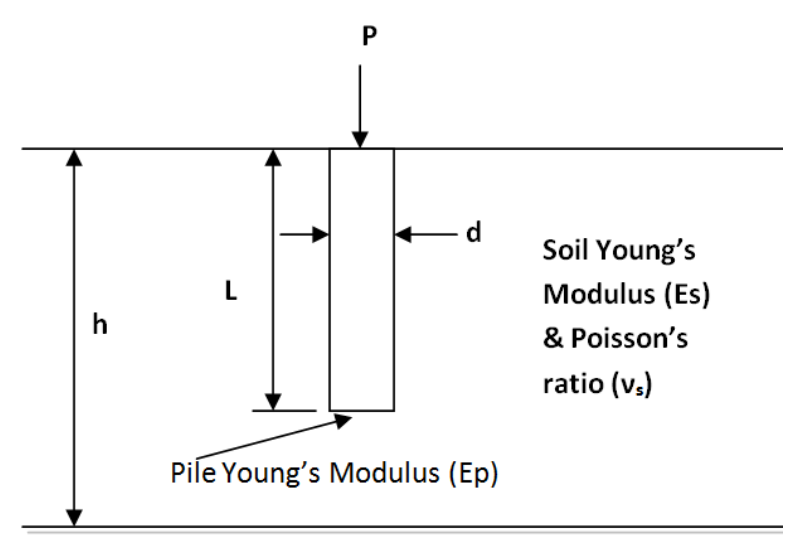

Rigid Stratum

Fig. 2 - Pile in elastic continuum

Combined stiffness of the pile raft system $\left[\mathrm{K}_{\mathrm{pr}}\right]$ has been obtained by summing up the stiffness of the soilraft system and the stiffness contribution at the pile locations.

$$
\left[\mathrm{K}_{\mathrm{pr}}\right]=\left[\mathrm{K}_{\text {plate }}\right]+\left[\mathrm{K}_{\text {soil }}\right]+\left[\mathrm{K}_{\text {pile }}\right]
$$

Where, $\left[K_{\text {plate }}\right]$ is the stiffness of the plate, $\left[K_{\text {soil }}\right]$ is the stiffness of the soil and $\left[\mathrm{K}_{\text {pile }}\right]$ is the stiffness of the piles. The force displacement equation of the piled raft system can be written as

$$
\left\{\mathrm{u}_{\mathrm{i}}\right\}_{\mathrm{c}}=\left[\mathrm{K}_{\mathrm{pr}}\right]^{-1}\{\mathrm{P}\}_{\mathrm{c}}
$$

$\left\{u_{i}\right\}_{c}$ is the generalised displacement at the nodes and $\{\mathrm{P}\}_{\mathrm{c}}$ is the applied external load at the nodes. By solving the above equation displacement parameters can be obtained.

\section{RESULTS AND DISCUSSIONS}

A computer code has been developed in FORTRAN language, based on the on theoretical study. It can determine the elastic settlement of raft foundation placed on elastic medium without and with piles at any location of the raft. The influence of introduction of pile on settlement can be studied and recommendations can be made for optimum use of piles for settlement control.

Analysis of a flexible raft foundation subjected to uniformly distributed load is carried out with and without pile foundation. The effect of number of piles, length of the pile \& pile dimensions on settlement is carried out to justify the efficacy of using pile raft foundation for settlement control.

\subsection{Comparative study of piled raft foundation}

To validate the theoretical study and the computer program a comparative study is carried out with a problem as given below [Mendonca and Paiva (2003)]" is considered.

A piled raft with dimensions $30.0 \mathrm{~m} \times 15.0 \mathrm{~m} \times 0.25$ $\mathrm{m}$, Young's modulus $\mathrm{E}=2.0 \times 10^{7} \mathrm{KN} / \mathrm{m}^{2}$ and Poisson's ratio $(v)=0.2$, is supported on soil and on nine piles (Fig. 3).

In the raft stiffened by the piles, the set of piles consists of groups $\mathrm{P}_{1}, \mathrm{P}_{2}, \mathrm{P}_{3}$ and $\mathrm{P}_{4}$. The mechanical properties of the soil are Young's modulus $\left(\mathrm{E}_{\mathrm{s}}\right)=2.0 \times$ $10^{5} \mathrm{KN} / \mathrm{m}^{2}$ and Poisson's ratio $\left(v_{\mathrm{s}}\right)=0.5$.

All the piles are of length $15 \mathrm{~m}$ and diameter $\left(\mathrm{D}_{\mathrm{p}}\right)$ $=0.3 \mathrm{~m}$ and when they are considered to be flexible, their Young's modulus $\left(\mathrm{E}_{\mathrm{p}}\right)$ is $=2.0 \times 10^{7} \mathrm{KN} / \mathrm{m}^{2}$. A uniform load $\mathrm{g}=30.0 \mathrm{KN} / \mathrm{m}^{2}$ is applied across the whole surface of the plate.

For study raft will be considered to be supported by nine piles as given in the Fig. $3 \& 4$.

The raft plate is discretised into 72 elements (12 division in the longer direction and 6 divisions in shorter direction) and the discretisation scheme for the above problem is in Fig. 5. 




Fig. 3 - Plan of the arrangement of piles below the raft foundation

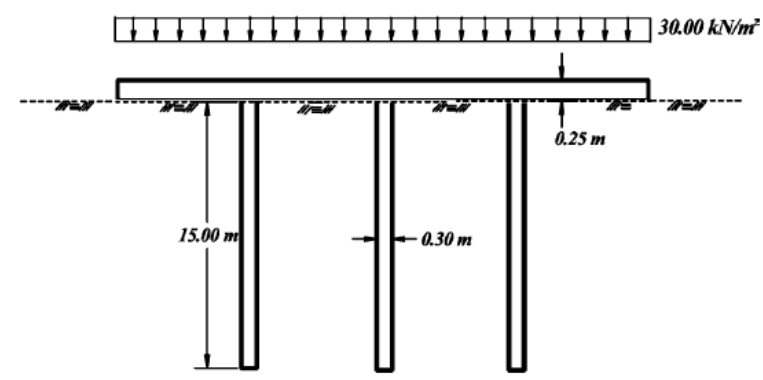

Fig. 4 - Sectional elevation of the Raft-pile system



Fig. 5 - Raft - soil interface discretisation

The result of the present analysis is compared with the solution obtained by Mendonca and Paiva (2003) and has been plotted in Fig. 6 .

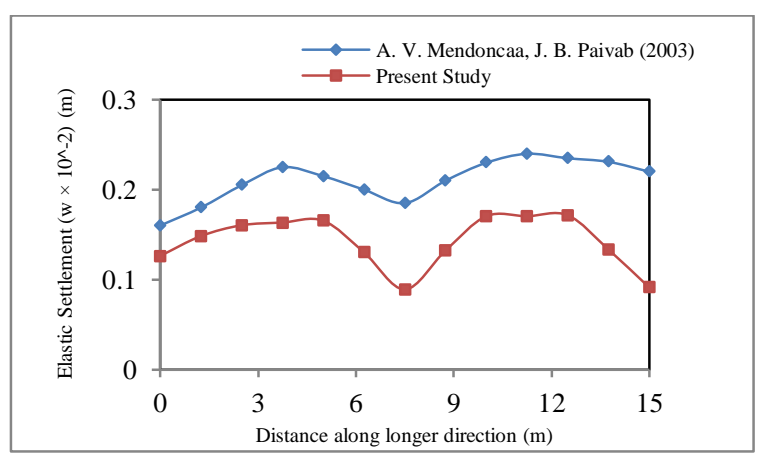

Fig. 6 - Elastic Settlement of the raft against distance along longer direction

The ranges of settlement predicted are in close proximity with the published result. The predicted settlements for the project study are on the lower side. This may be attributed to the modeling of the raft as a thick plate which considered shear deformation into account.

\subsection{Analysis of Rectangular Piled Raft Foundation}

A rectangular raft of dimension $15 \mathrm{~m} \times 9 \mathrm{~m}$, thickness $0.5 \mathrm{~m}$ is placed on a soft soil deposit having soil modulus $\left(\mathrm{E}_{\mathrm{s}}\right)=2 \times 10^{4} \mathrm{KN} / \mathrm{m}^{2}$ and Poisson's ratio $\left(\mu_{\mathrm{s}}\right)=0.4$. Raft modulus $\left(\mathrm{E}_{\mathrm{p}}\right)=2.5 \times 10^{7} \mathrm{KN} / \mathrm{m}^{2}$ and Poisson's ratio $\left(\mu_{\mathrm{r}}\right)=0.2$. Loading; uniformly distributed $\left(500 \mathrm{KN} / \mathrm{m}^{2}\right)$.

The above problem on a rectangular piled raft foundation has been analysed with different arrangement of piles and considering different length and diameter of pile.

The different cases are shown below.

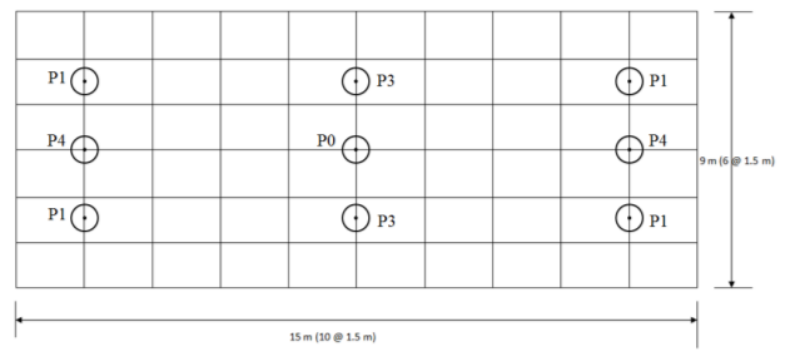

Fig. 7 - Case-1: The piled raft foundation with 9 piles

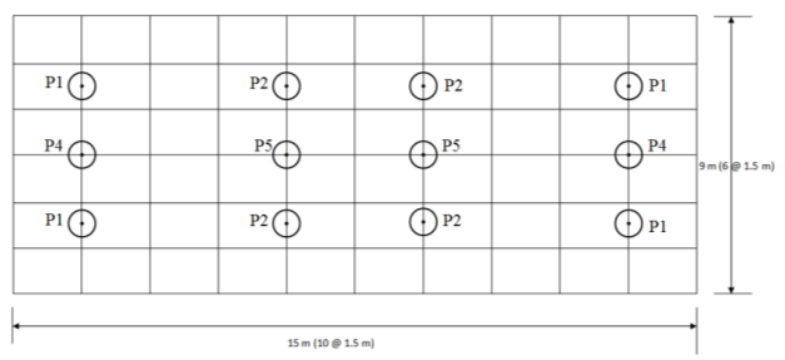

Fig. 8 - Case-2: The piled raft foundation with 12 piles

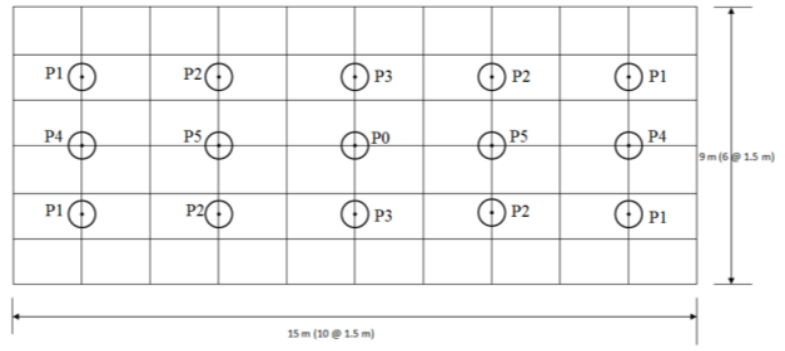

Fig. 9 - Case-3: The piled raft foundation with 15 piles

The evaluated elastic settlement of the piled raft foundation without pile against distance along longer direction has been plotted in Fig. 10. 


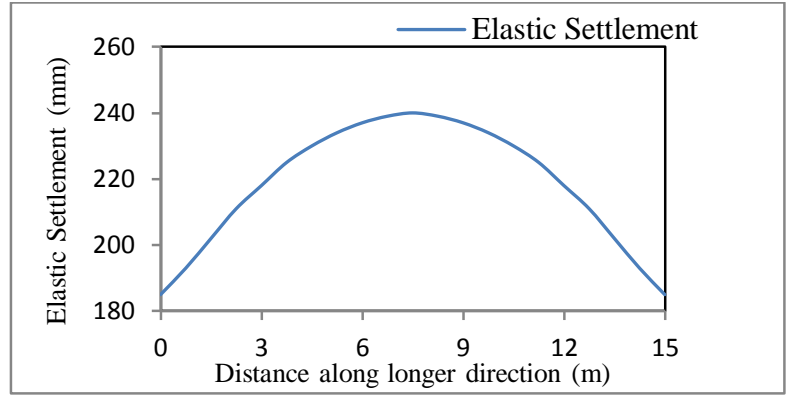

Fig. 10 - Elastic Settlement of the raft without pile against distance along longer direction

Elastic Settlement of the piled raft foundation considering diameter of pile $0.5 \mathrm{~m}$ and pile length 15 $\mathrm{m}$, has been determined with different no. of piles. The calculated result has been plotted in Fig. 11.

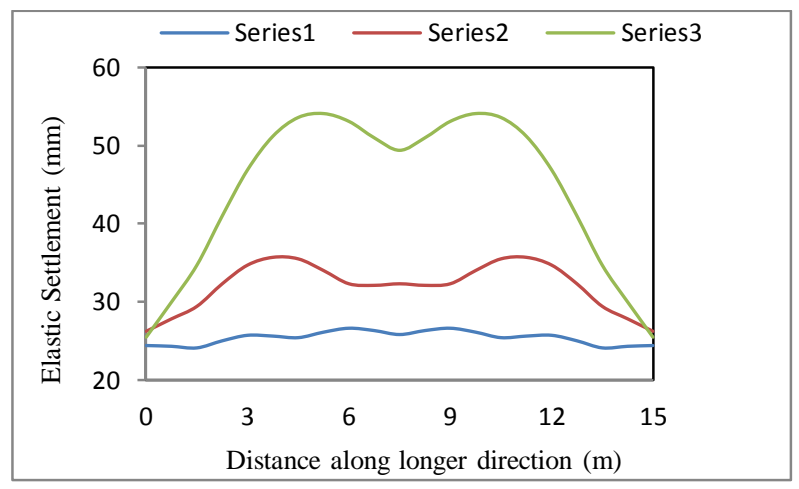

Fig. 11 - Elastic Settlement of the piled raft foundation against distance along longer direction. (Series1 for using 15 nos. of piles, Series 2 for using 12 nos. of piles and Series 3 for using 9 nos. of piles)

Elastic Settlement of the piled raft foundation considering diameter of pile $0.3 \mathrm{~m}$ and pile length 15 $\mathrm{m}$, has been determined with different no. of piles. The calculated result has been plotted in Fig. 12.

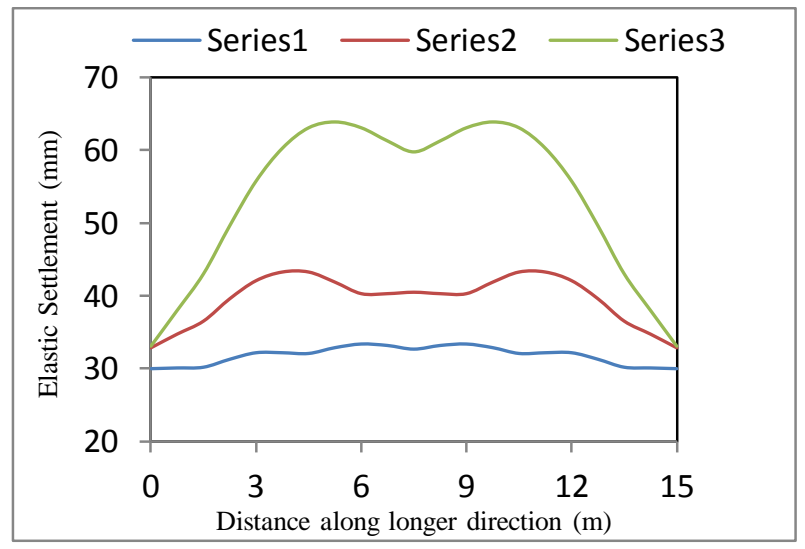

Fig. 12 - Elastic Settlement of the piled raft foundation against distance along longer direction. (Series1 for using 15 nos. of piles, Series 2 for using 12 nos. of piles and Series3 for using 9 nos. of piles)
Elastic Settlement of the piled raft foundation with 15 piles and considering diameter of pile $0.5 \mathrm{~m}$, has been determined with different length of piles. The calculated result has been plotted in Fig. 13.

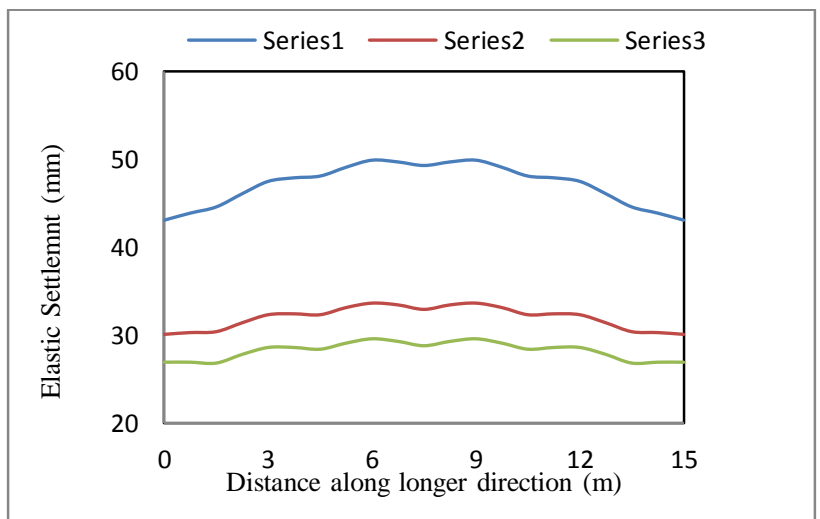

Fig. 13 - Elastic Settlement of the piled raft foundation against distance along longer direction. (Series 1 for considering length of piles $5 \mathrm{~m}$, Series 2 for considering length of piles $10 \mathrm{~m}$ and Series 3 for considering length of piles $12 \mathrm{~m}$ )

The predicted maximum settlements of the piled raft foundation have been plotted against number of piles in Fig. 14.

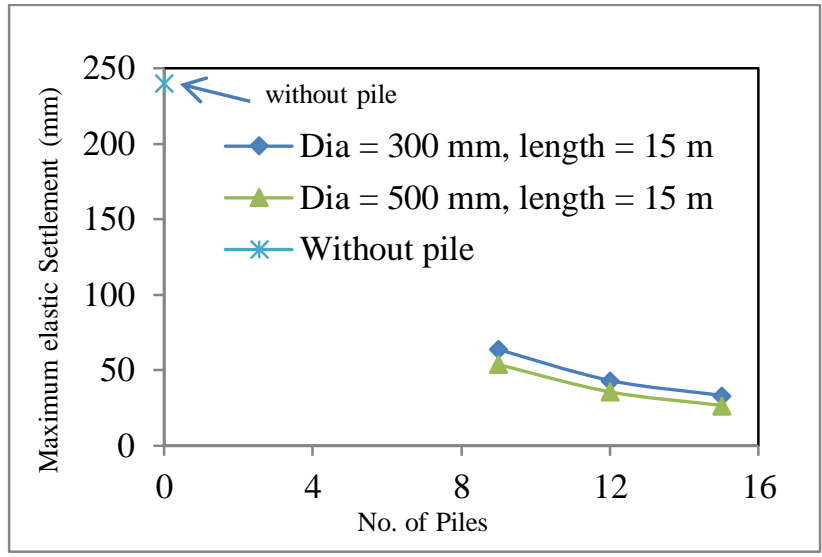

Fig. 14 - Predicted maximum settlements against different no. of piles

The predicted maximum settlements of the piled raft foundation against different length of piles have been plotted in Fig. 15. 


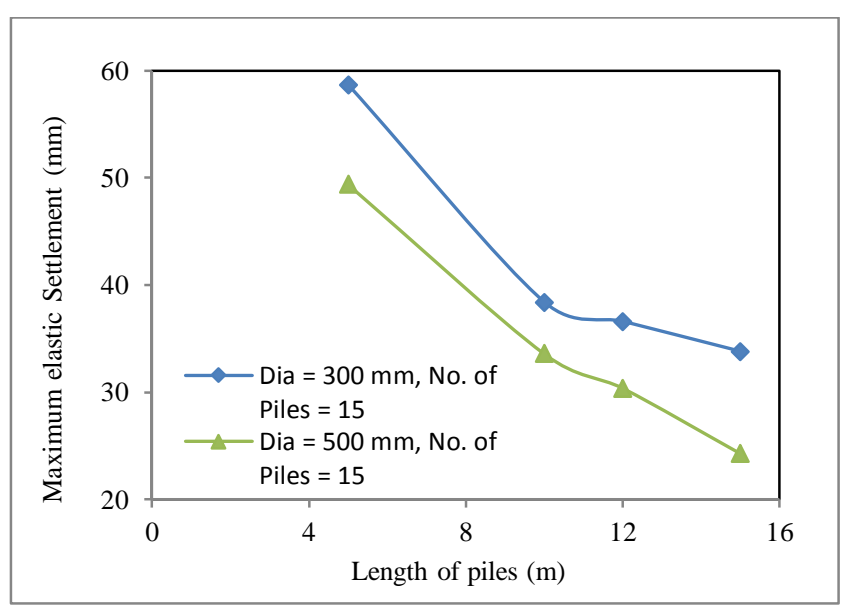

Fig. 15 - Predicted maximum settlements against different length of piles

It can be observed from Fig. 14 \& 15 that introduction of pile in the system reduces the maximum settlement quite considerably. Optimum no. of piles, different length of piles and configuration can be determined depending on the requirement of settlement consideration for a particular problem. Suitable selection of raft thickness and pile configuration can be chosen for optimum design of the piled raft foundation system.

\section{CONCLUSION}

The developed computer programme is used for prediction elastic settlement of rectangular raft foundation. The primary objective of the study is to develop an approach for optimization of piled raft foundation system. The present study has demonstrated that piled raft foundation can be used to reduce elastic settlement. It is observed that use of piles leads to reduction of total as well as differential settlement. The effect of pile dimensions, length of pile and the arrangements of piles on the performance of a piled raft foundation has been studied. below:

The conclusive remarks can be summarized as

i. A couple BEM - FEM formulation for the analysis of piled raft has been presented in which all the interactions between the plate, the pile and the soil are considered.

ii. The developed computer programme shows good convergence with lesser number of elements. This highlights the suitability of the coupled approach.

iii. Both the stiffness of the raft and piles has a major role in determining the elastic settlement of piled raft foundation.

iv. It is observed that introduction of piles in the system reduces settlement considerably. Hence piled raft can be used to minimize the elastic settlement as required. v. Elastic settlement is reduced with increasing of diameter of piles, as the stiffness of pile will increase.

vi. For same configuration of piles elastic settlement reduces with increment in length of pile.

\section{REFERENCES}

1) Mandal, J. J. and Ghosh, D. P. (1999): Prediction of Elastic Settlement of Rectangular Raft Foundation - A Coupled FE-BE Approach, International Journal for Numerical and Analytical Methods in Geomechanics, 23, $263-273$.

2) Mendonca, A. V. and Piava, J. B. (2003): An Elastostatic FEM/BEM Analysis of Vertically Loaded Raft and Piled Raft foundation, Engineering Analysis with Boundary Elements, 27, $919-933$.

3) Mindlin, R. D. (1936): Force at a Point in the Interior of a Semi-Infinite Solid, Physics, 7, 227 235.

4) Poulos, H. G. and Davis, E. H. (1980): Pile Foundation Analysis and Design, New York, John Wiley. 